\title{
Economic Recovery Enabled by Technologies
} A Case Study on the Issuance of Consumer Coupons in Yantai
of Shandong Province

\author{
Anqi Wang* \\ School of Government and Public Affairs, Communication University of China, Beijing, 100000, China \\ *Corresponding author. Email: 1035844156@qq.com
}

\begin{abstract}
At the beginning of 2020, the COVID-19 epidemic is raging around the world. Such a public crisis has slowed or even stalled economic development, but unlike the SARS pneumonia epidemic, under the background of 'Internet +', the construction of cloud platform and big data technology have increased the powerful chips for the recovery and reconstruction in the post-crisis period. This paper analyses the promotion process of issuing consumer coupons in Yantai, Shandong Province, relying on the ten principles of economics, welfare economics, public sector economics, then getting the conclusion that under the macro-control of the government, the new media and big data technology can also promote the recovery of the cultural tourism market, promote the recovery of the local economy, and then promote the establishment of better trust between the government, enterprises and citizens. Studying the contribution of the technology for economic has good guiding significance for the exploration and construction of local new media, the resumption of production under the regular prevention and control of epidemic situation and the recovery of consumer market.
\end{abstract}

Keywords: Macro-control, Technology, Economic recovery.

\section{INTRODUCTION}

At present, the impact of the COVID-19 economic market cannot be underestimated. First of all, the epidemic continues to spread, the resumption of work continues to delay, the implementation of the urban closure policy has led to a significant reduction in commodity demand. All kinds of enterprises in the supply chain face different operating obstacles, upstream enterprises are mainly affected by labor shortage, while downstream enterprises face more severe challenges in supply chain and consumer demand. The industry difference is huge. Secondly, a kind of 'Homestead Economy' came into being; relying on the Internet and cloud platform, the demand of network users is also increasing day by day. Homestead economy[1] originated earliest from 'lazy economy', a new concept with the rise of the network, its essence is the continuous refinement of social division of labor, mainly refers to home life and home consumption. In this extraordinary period, home consumption has been remolded again, and the people of the whole country have jointly cultivated a new type of consumption habits in a way of last resort. Besides, the trend behind the home economy is the current and future investment trend, and these industries may usher in a new development of 'tuyere'. In response, the central government advocated that as the situation of prevention and control of the epidemic continued to improve in China, various industries resumed production and work steadily, while the intensity of new kinetic energy consumption on-line was not reduced, offline consumption scenes such as scenic spots, restaurants and hotels returned to the public view. The resumption of consumer demand which was been forced to delay during the outbreak prevention and control period has restarted again. Encourage local governments to issue consumer coupons to promote the recovery of consumer markets and release consumption potential[2].With the effect of short-term stimulus measures such as issuing consumer coupons, the recovery and boost of the consumer market are obvious to all.. Yantai City, Shandong Province, in the process of issuing consumer coupons to promote economic recovery, relying on the new media cloud platform and big data technology, created an innovative path to promote economic recovery, to achieve ' $1+1>2$ ' effect. 


\section{CASE BRIEF}

Since the publication of the notice on issuing consumer coupons to promote consumption recharge and potential release on April 2, Yantai City, Shandong Province, has issued a series of policies and issued three consecutive rounds of consumer coupons. The implementation of consumer coupons will help to combine the resumption of work with the expansion of domestic demand, and quickly drive the recovery and development of enterprise development service industry. The implementation of consumer coupons will help show the concern and care of the society, truly benefit the broad masses of the people, and promote the improvement of people's livelihood. This Circular is issued in accordance with the Opinions of the Provincial Party Committee and provincial government on Comprehensively Promoting coVID-19 Epidemic Prevention and Control and Economic and Social Development in the Spirit of Implementing the Important Speech of General Secretary Xi Jinping, We will encourage local governments to issue consumer coupons in line with their actual conditions, promote faster recovery of consumption, effectively unleash consumption potential, and promote the healthy development of the service sector.

At April 28, 'people from Shandong province visit Penglai' event started online, showing Penglai, a country's Home AAAAA level scenic spots through the new media live broadcast, and live purchase of half-price tickets. This event abstracted more than 400,000 visits, being praised by over 20,000 .It is aimed at the new situation of the current cultural tourism work, to provide the people with innovative preferential policies and quality tourism services.

Since May 1, Yantai issued a total of 30 million yuan of consumer coupons. This issuance of consumer coupons is different from the previous balanced distribution of big net fishing types. Instead, big data of Tencent is used to analyze the consumption capacity of various aspects of clothing, food, housing, transportation, and targeted issuance of consumer coupons of different amounts. Citizens can search through WeChat 'Yantai Huimin consumer coupons' Mini Programs and the Municipal Bureau of Commerce WeChat public number for advance booking and shake number. Therefore, citizens can apply for electronic consumer coupons and the full amount of consumption offset without going out. At the same time, the issuance of consumer coupons in the cultural tourism market is also a new way.

The online platform of 'Shandong Culture and Tourism Huimin Consumption Season' was launched on March 28 this year, is the first intelligent public service platform in the province. It realizes the functions of live broadcast, online ticket purchase, travel reservation and so on, and provides a new network space. The recent cultural tourism consumption season relies on this online platform for the issuance of electronic consumer coupons. One month after the issuance of electronic consumer coupons, the city's key monitored scenic spots increased by 267 percent, operating income increased by 187 percent, tourists' willingness to travel increased strongly, and the trend of market recovery was obvious.

\section{ECONOMIC THEORY FOR ISSUING CONSUMER COUPONS}

Welfare economics [3], which is an economic theory system to study social and economic welfare. It was founded in the 1920s by British economists Hobbes and Pigou. Advocate equalization of national income, established utility basis theory and so on. Economics distinguishes empirical economics from normative economics. Empirical economics[4] which excludes the theoretical economics of social evaluation, studies the operation of the economic system, explains how and why the economic system operates, and answers the questions of 'YES' and 'NO' to answer the question. The task of normative economics is to make a social evaluation of the operation of the economic system and to answer the questions of 'good' and 'bad' questions.

Welfare economics belongs to normative economics [5]. The main content is that 'The more equal the distribution is, the greater the social welfare is', which advocates the equalization of income, thus the 'welfare state' are emerging. The strengthening of the role of the state in the process of national income regulation has made the national income equally.

'Benevolent Social Planner' in welfare economics mentioned that if the allocation of resources maximizes total surplus, we can say that this allocation is efficient [6]. In the market, how to ensure the maximization of total surplus in various situations is a matter for decision makers to consider carefully. The negative residual value of the producer and consumer side will have a great impact on the market and will also hit the confidence value of the corresponding party. At this point, the government's macro-control role is crucial, the invisible hand needs the government to protect it. Only when property rights are guaranteed can the market run. There are two types of reasons for government intervention in the economy: promoting efficiency and promoting equality. According to article 7 of the ten principles of economics, governments can sometimes improve market outcomes. Markets, as invisible hands, consider all information about buyers and sellers, so in general, free markets are the best way to organize economic activity [7]. But at the same time, markets sometimes fail, concentrating on uneven resource allocation. At this point, public policy can correct these problems and improve failure, thus increasing economic efficiency. There are two ways to 
improve economic efficiency, in which governments can adopt market-based policies to encourage producers to solve problems themselves. The study believes that this approach is more personalized than direct government control and orders, thus avoiding resistance from different producers because of different personal confidence in the average policy issued by the government.

Apart from some competitive and exclusive goods, there is another category of goods in the market, public goods [8], public goods are things that can be shared, strictly speaking, and public goods are non-competitive and non-exclusive. The so-called non-competitive means that one's consumption of public goods does not affect their supply to others, which means that at a given level of production, the marginal cost of providing this item to another consumer is zero. The so-called non-exclusive refers to someone in the consumption of a public good, which other people cannot be excluded to consume (whether they pay or not), or whose cost of exclusion is very high. The so-called exclusivity of a commodity means that the producer or purchaser of a commodity can easily exclude others from obtaining the benefits of the commodity; the competitiveness of a commodity means that the quantity of a consumer commodity is related to the cost of producing that quantity. People's demand for public goods is more flexible [9]. In fact, there are many cost-benefit problems in the cultural tourism market. When private producers cannot provide enough economic benefits, the government needs to support it through contract outsourcing. But at the same time, when the government decides to support the construction and delivery of the public goods, it also needs to consider the total income of all consumers who use the public goods and the cost of the maintenance and repair of the public goods.

\section{TECHNOLOGY ENABLES ECONOMY}

Compared with the SARS epidemic, the epidemic is in the environment of 'Internet +', where both propaganda and economic recovery have an innovative path compared with 2003. First of all, compared with 2003, Today's Chinese economy has shifted from rapid growth to a new normal. In this case, the economic resistance will be weakened. Secondly, the industrial structure and SARS period of China's economy have changed greatly at this stage. The growth pressure brought by the tertiary industry will be far greater than that during the SARS period. Thirdly, our trading environment today is much more complex than it was in 2003.

Since the central government issued the request to establish an integrated online platform for government services, all localities have begun to build online platforms, so that mobile phones can show people information conveniently than ever since. The development of new media technology and big data analysis also provide a statistical support point for economic recovery, so that the economy can move in the right direction.

New Media technology [10], is the best choice for the network economy and the media industry to realize the docking with the information service function as the media. The new media with the dual attributes of society and economy has the responsibility of spreading advanced culture. What's more, there is also a need for profit. As the most popular word in the IT industry, big data has gradually become the focus of profit for industry personnel to chase after the following data warehouse, data security, data analysis, data mining and so on centering on the use of the business value of big data. With the advent of big data analysis also came into being. There are six basic aspects of big data analysis: The first way is visual analysis. The second one is data mining algorithm. The third one is predictive analysis ability. The fourth one is semantic engine. The fifth one is data quality and data management. The sixth one is data warehouse. During the design of business intelligence system, the construction of data warehouse is the key and the foundation of business intelligence system. It undertakes the task of data integration of business system, provides data extraction, conversion and loading (ETL) for business intelligence system, and queries and accesses data according to topic, and provides data platform for online data analysis and data mining.

Based on this, new media technology has broken the limitation of time and space, not only to help producers reduce production costs, but also to help consumers increase consumer confidence. The role of new media technology in various sudden public crises is also becoming increasingly important. In economic development, the information of producers and consumers can be collected through big data platform, which is helpful for the government to regulate and control the market in time, so as to effectively avoid the serious economic crisis. The most critical point is that in the market, consumers are also doubtful whether the value of goods is true or not. New media technology can promote the rapid building of trust between producers and consumers and reduce the irrelevant costs of producers and consumers.

\section{CONCLUSIONS}

Under the background of current market failure, government intervention and macro-control are the inevitable choice to promote economic recovery and play the same role as fuel. With the development of the Internet, technology plays the role of combustible agent, can promote faster economic recovery relying on new media and cloud platform construction. The maturity of new media technology promotes better trust between 
governments, businesses and citizens. At the same time, the exploration and knowledge of new technology also counteracts the development of new media and the construction of integrated online platform, which can be said to be a win-win result.

\section{REFERENCES}

[1] Chuanjiang Liu, Lingyun Zheng. Ten Great Effects on Traditional Economics Theory by Economic Informationization[J]. Journal of Zhongnan University of Economics and Law, 2002, 5(5):14-14.

[2] Xiaofi Hou, Research On the Application of Environmental Policy Tools from The Perspective of Welfare Economics [J]. Perspective Journal of Hebei University of Geosciences, 2020(3):91-99.

[3] Hongyou Lu, Yu Qi. Public Sector Economics: Evolution and Development Trends [J]. Research on Financial Issues, 2013, 7:64-71.

[4] Xiaohua Li. House Economy: Connotation, Evolution and Drivers Factors [J]. Enterprise economy, 2020, 477(5):5-15.

[5] Shandong Provincial Commerce Bureau. Notice on the Issue of Consumer Vouchers to Promote Consumption Replenishment and Potential Release [EB/OL]
[6] Doulos I G, Katsoulakos N, Kaliampakos D C .The Electricity Market Structure in Greece and the Paradox of Renewable Energy Sources[J]. Journal of Power and Energy Engineering, 2019, 7(4): $1-26$.

[7] Zuoshi Xie, Ping Li. The Origin, Content and Re-interpretation of Milton Friedman's Positive Economics Methodology [J].The Journal of World Economy, 2007, 30(12):64-74.

[8] Schmidt S .A Proposal for More Sophisticated Normative Principles in Introductory Economics [J]. The Journal of Economic Education, 2017, 48(1):3-14.

[9] Mankiw, Principles of Economics [M]. Beijing: Peking University Press, 2015.156

[10] Mankiw, Principles of Economics [M]. Beijing: Peking University Press, 2015.159

[11] Jianhua Cheng, Jingzhou Wu, Diversified Supply of Public Goods in China [J]. Price Theory and Practice, 2007, 10:29-30.

[12] Aixue Wang, Dingtao Zhao. Theoretic retrospect and prospect of Western public products [J]. Jianghuai Tribune.2007(4): 38-43.

[13] Qing Chen, Technology and Market Advantage and Path Choice of New Media Economy Development in China [J]. Modern Communication, 2018, 40(12):128-131. 